\title{
A SURVEY OF RECENT DEVELOPMENTS IN THE TREATMENT OF PNEUMOCOCCAL MENINGITIS
}

BY

\author{
W. P. U. JACKSON, M.A., M.D.(Cantab.), M.R.C.P., D.C.H. \\ From the Department of Clinical Medicine, University of Cape Town
}

(Received for PUblication June 28, 1949)

Doctors cure few diseases. When even an occasional patient begins to recover from a disease which previously carried $100 \%$ mortality, an impressive advance has been made, and when, later, such patients are actually expected to recover, then medicine may claim a triumph. This has happened with regard to pneumococcal meningitis.

Pneumococcal meningitis is not common, and no large series of cases have been described in Great Britain except those of Cairns and his co-workers at Oxford (Cairns et al., 1944 ; Smith et al., 1946). These particular reports were not fully representative of the general run of cases for at least two reasons; first, the great majority of these patients were adults, many being members of the armed forces, and secondly the treatment was carried out by a highly skilled team with the finest possible neurosurgical skill constantly at hand. For this reason, and bearing in mind that single cases are still being published, it was considered of interest to collect and analyse case records from different hospitals over the period of modern chemotherapy, tracing the changes in mortality rates as different agents were used, and then attempting to assess the present therapeutic value of penicillin and the most judicious method of its employment. For this purpose the records for the 11 years 1938-1948 of four large hospitals in Birmingham have been used. Several of the more recent cases have been seen personally. Before reviewing the Birmingham cases a short survey of the literature will usefully place them in perspective.

The Pre-Chemotherapentic Era

Goldstein and Goldstein found 150 recoveries reported in the literature up to 1927, and Steele and Gottlieb (1941) found a further 30 between 1927 and 1939. (Incidentally horse antiserum was introduced in 1930, but was evidently not very effective.) Two large single series with $100 \%$ mortality rates were those of Toomey and Roach (1939) from Ohio (159 cases), and of Silverthorne (1948) from Canada (121 cases).

The majority of recoveries reported seem to have been in those cases which were secondary to ear disease, and perhaps the primary condition had really produced a local arachnoiditis rather than a more general leptomeningitis in these patients. Certainly some such explanation must be suggested for the remarkable report of Adam and Connal (1937) of seven recoveries from nine cases, especially since their radical treatment of the otitic state itself, as soon as meningitis was suspected, was so successful. Allman (1937) published an account of another recovery in an otitic case in the same year.

TABLE 1

Results of Chemotherapy In the Later Sulphonamide Era

\begin{tabular}{|c|c|c|c|}
\hline Author & No. of Cases & Recoveries (\%) & Remarks \\
\hline $\begin{array}{l}\text { Better Results } \\
\text { Rhoads et al. (U.S.A., 1940) } \\
\text { Hodes et al. (U.S.A., 1943) } \\
\text { Appelbaum (U.S.A., 1945) } \\
\text { Jaffe (South Africa, 1946) } \\
\text { Walker and James (U.S.A., 1945) }\end{array}$ & $\begin{array}{r}22 \\
60 \\
139 \\
24 \\
5\end{array}$ & $\begin{array}{r}32 \\
42 \\
35 \\
41 \\
4\end{array}$ & $\begin{array}{l}\text { Radical surgical treatment of primary } \\
\text { focus }\end{array}$ \\
\hline $\begin{array}{l}\text { Poorer Results } \\
\text { Sweet et al. (U.S.A., 1945) } \\
\text { Dowling et al. (U.S.A., 1942) } \\
\text { Silverthorne (Canada, 1948) } \\
\text { Present series (Birmingham) }\end{array}$ & $\begin{array}{l}40 \\
72 \\
47 \\
82\end{array}$ & $\begin{array}{l}7 \cdot 5 \\
5 \cdot 5 \\
14 \\
20\end{array}$ & $\begin{array}{l}\text { Pooled cases } \\
\text { Pooled cases }\end{array}$ \\
\hline
\end{tabular}




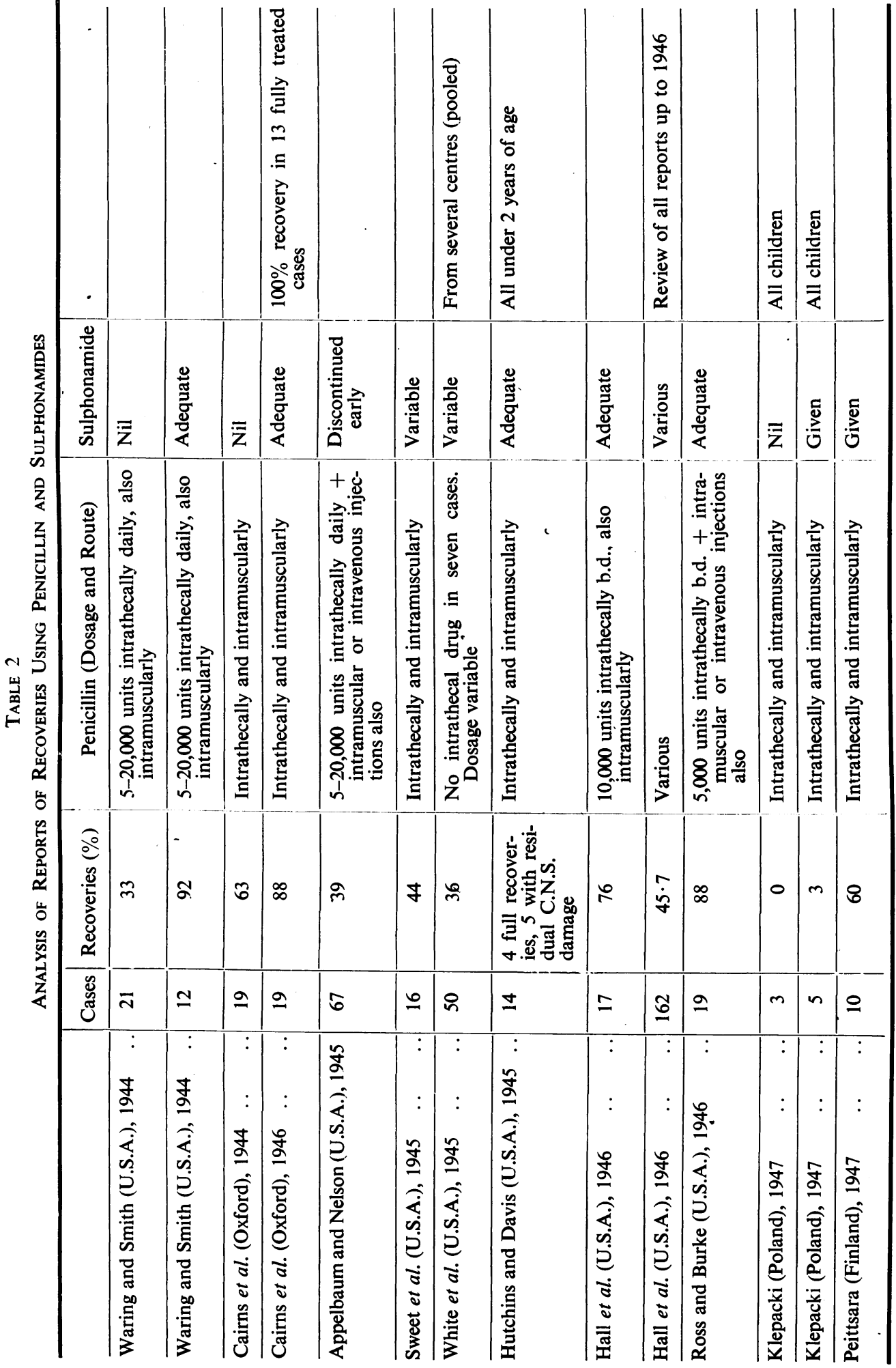

$\frac{\rho}{\bar{\partial}}$

蛋

음

क

$\overrightarrow{0}$

$\overrightarrow{\vec{\omega}}$

气

or

$\vec{N}$

N

옥

$\overrightarrow{3}$

$\frac{\text { న్ }}{\frac{1}{3}}$

응 
The Early Sulphonamide Era

In June, 1937, Mertins and Mertins recorded the recovery of an otitic case on prontosil, and in the same month Caldwell and Byrne described the cure of a non-otitic patient, but unfortunately pneumococci were not actually isolated on culture. In 1938 Finland et al. reported six recoveries in ten cases treated with sulphanilamide combined with frequent complete cerebrospinal fluid drainages and specific rabbit antiserum given intrathecally. Reid and Dyke (1938) were the first to claim recovery after the use of sulphapyridine. By 1939 more than 30 cures had been reported (Hewell and Mitchell). Raman (1939) claimed to have cured the first case after a true single relapse, using sulphapyridine.

There was, as usual, a tendency to report only good results, and Steele and Gottlieb in 1941 found 115 cases in the literature treated with sulphanilamide or sulphapyridine with a $66.6 \%$ recovery rate. In this collection the results with sulphanilamide were slightly better than those with sulphapyridine. Antiserum given in addition was found to be valueless. No recovery had been described under the age of two years. Of the larger series, MacKeith and Oppenheimer (1939), Neal et al. (1940), and Leyshon (1942) reported a high proportion of recoveries $(45 \%$ in 47 cases). In the present series from Birmingham there were no recoveries in the 17 cases treated with sulphanilamide only.

The Later Sulphonamide Era

A whole spate of papers now appeared reporting very variable results of treatment. A few quotations will suffice.

It is noteworthy that two series from the poorer result group were pooled from various hospitals. Thus Dowling's 72 cases were the total number notified in the city of Washington between January, 1938, and December, 1942. This series includes cases treated by all types of sulphonamide.

The Penicillin Era

Reported cases and series now become extremely difficult to analyse because of differences in the dosage, purity, and route of injected penicillin, and because of the variable combination of sulphonamides with it. These new distinctions between different accounts, and even within single series, added to the existing variabilities (e.g. age of patients; pooled, single-hospital or single-team series; dosage and type of sulphonamide) render doubtful the value of comparisons. Moreover the importance of several reports is greatly diminished by the complete omission of any statement regarding these factors as they apply to any particular series.

Barker in December, 1943, published the first account of a recovery after the use of penicillin, and at almost the same time Keefer et al. (1943) reported 23 cases with seven recoveries, but their dosage was small and the intrathecal route was frequently not used. Other reports may be compared in tabular form (Table 2).

It must be admitted that some of these results are no better than those reported by Appelbaum (1945) and by Hodes, Smith, and Ickes (1943) using sulphonamides only. However, a truer picture of the value of modern treatment is obtained by considering together those series in which more or less full and adequate therapy was given. Taking cases which received 5,000-40,000 units of penicillin intrathecally at least daily for not less than five days, together with adequate sulphonamide dosage, it is found that a recovery rate of $79 \%$ is recorded in 101 patients. This figure would probably be improved further if patients who died within a few hours of admission to hospital were excluded.

\section{Present Series}

The quotations in Table 2 demonstrate the value of continuing sulphonamides with penicillin, the superiority of this combined therapy being evident throughout.

Table 3 calls for little comment. If only those cases which were adequately treated with penicillin and sulphonamides and did not die within $\mathbf{4 8}$ hours of admission are considered separately, there are 24 cases with 17 recoveries $(72 \%)$.

Table 4 accentuates the poorer prognosis in young

TABLE 3

Analysis of Treatment in Present Series

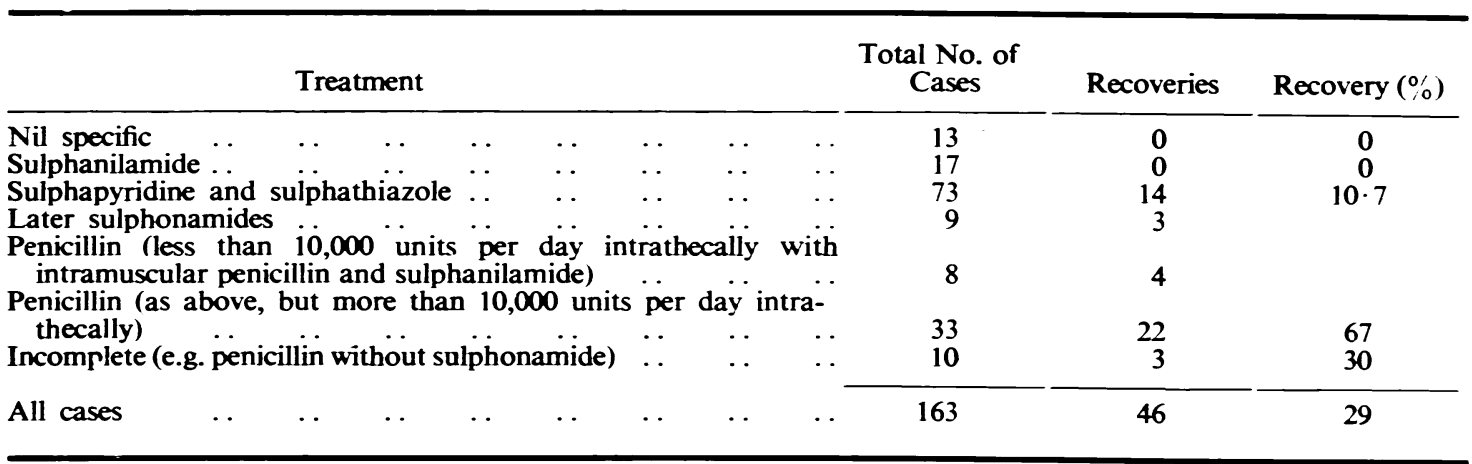


TABLE 4

Prognosis Related to Age

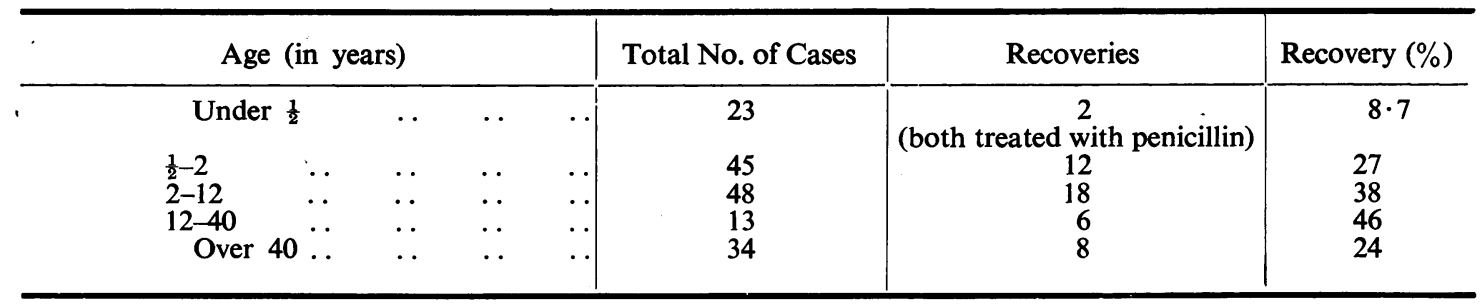

infants, a feature also noted during the sulphonamide era by Hodes et al. (1943), Alexander (1943), and Jaffe (1946). Steele and Gottlieb (1941) remarked that, despite $66.6 \%$ recoveries in 115 reported cases in the earlier sulphonamide days, all cases under 2 years of age had died. Indeed, recoveries in infants before the use of penicillin were rare, although Jacobsen (1945) reported a baby of 3 months cured with sulphapyridine, and another of 14 months, out of a total of 14 patients. The use of penicillin has so greatly improved the prognosis in the infant that White et al. (1945) thought it no different from that of the adult, and Ross and Burke (1946) reported a series of nine cases under the age of one year, all of whom recovered. Nevertheless such results cannot be claimed by all (Waring and Smith, 1944; Hutchins and Davis, 1945; Klepacki, 1947).

There were also a few cases of peritonitis (3), empyema (2), endocarditis (2), bronchitis (1), and meningocoele (1).

These figures bear out the suggestion of Hodes, Smith and Ickes (1943) that meningitis secondary to a pneumonia carries a worse prognosis, but White et al. (1945) on the other hand consider that a primary focus in the head is worse than a pulmonary one.

No serious cerebral sequelae were recorded, unlike those in the series of Hutchins and Davis (1945), and Jaffe (1946). Spinal block during intrathecal penicillin therapy was suspected only once, and this was doubtful. Neither cerebral abscess, cauda equina damage, nor residual mental defect was noted.

One curious feature was the occurrence of unilateral orbital oedema of quite gross degree in three cases, two seen personally. The swelling came on in each case a day or two after the onset of the meningitis, and was not combined with any proptosis. In one case (Case 8) it was accompanied by complete third nerve palsy of that side. There were no fundal changes. The oedema cleared up within ten days in all cases. In view of the frequency with which cerebral venous thromboses are found at necropsy in cases of pneumococcal meningitis, it seems likely that this orbital oedema was caused by thrombosis of an orbital vein.

\section{Deaths Despite Apparently Full and Adequate Treatment}

Cairns and his co-workers (Smith et al., 1946) consider that there is no reason why the general mortality, rate for pneumococcal meningitis should not be as low as $10 \%$, which figure they succeeded in reaching in their own later series. Among the present cases there appear to have been 24 who were fully treated with intrathecal and systemic penicillin and sulphonamides on the lines advocated by Cairns, and on whom the greatest care was expended. None who died within 48 hours of admission are included. Nevertheless seven succumbed.

\section{Case Reports}

Case 1. Aged 12 months. Complicated by diarrhoea. Died two days after admission. Gross hepatic damage evident at necropsy.

Case 2. Aged 4 months. Meningitis was a complication of pneumococcal peritonitis. The C.S.F. could not be completely cleared of the organism, which persisted despite raising of the intrathecal dosage to 100,000 units daily. Death after 30 days' treatment in status epilepticus. No C.S.F. block. No evident reason for lack of response was found at necropsy. Was the epilepsy due to the disease or to the (pure) penicillin ?

Case 3. Aged 13 months. Child developed left hemiplegia, choreiform movements, and recurrent fits. The C.S.F. remained sterile for 11 days before death. No hydrocephalus was found, but presumably severe functional brain damage had been caused.

TABLE 5

Apparent Primary Conditions

\begin{tabular}{lll|c|c|c|c|c|c|}
\hline & & None & Middle-Ear Disease & Pneumonia & Tonsillitis & Sinusitis \\
\hline Total No. & & $\ldots$ & $\ldots$ & 47 & 36 & 33 & 6 & 3 \\
Recovery rate $(\%)$ & $\ldots$ & $\ldots$ & 39 & 50 & 18 & 50 & 0 \\
\hline
\end{tabular}


TABLE 6

COMPLicATIONS ReCORDED

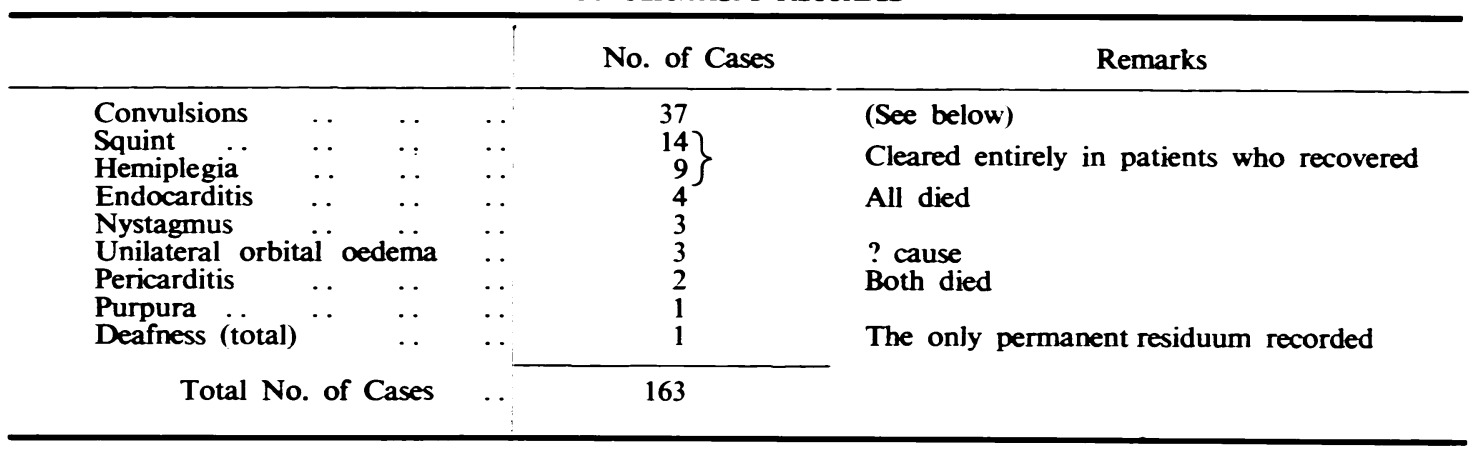

Case 4. Aged 6 weeks. There were at least seven days before treatment was started and a grossly bulging fontanelle presented on admission. Lateral and superior sagittal sinus thromboses were found at necropsy.

Case 5. Aged 2 years. No apparent response whatever. Death after two days' treatment, with terminal convulsions. Dosage of intrathecal penicillin was 40,000 units of the pure salt. No reason was found for lack of effect on the C.S.F.

Case 6. Aged 48. Left lower lobar pneumonia was the primary condition. Death after three days, with no apparent reason for failure of sterilization of the C.S.F.

Case 7. A boy aged 17 months was admitted to hospital with a diagnosis of right mid and lower pneumonia (W.B.C., 33,000). Treatment was begun with intramuscular penicillin, 25,000 units threehourly, and sulphamezathine, $1 \mathrm{~g}$. and $0.5 \mathrm{~g}$. four-hourly. Progress was excellent until nine days after admission when neck rigidity was noticed, without fever or apparent illness, and pneumococci were isolated from the C.S.F. Treatment was continued as before, but in addition intrathecal pure penicillin (25,000 units) followed by 10,000 units daily was given. The C.S.F. rapidly cleared, but 16 days after admission organisms reappeared in the C.S.F., with rapid clearance again. Twenty days after admission the child was worse, and had right sided convulsions with remaining right hemiplegia.

Twenty-six days after admission the child was again worse, with vomiting and further fits, and serous discharge from the right ear. Organisms were again found in the C.S.F. The baby was transferred to the neurosurgical department, where ventriculography was performed but no block or abscess was discovered. Culture was positive (cells 1,044). Intraventricular pure penicillin $(20,000$ units daily) was given.

Twenty-seven days after admission the ventricular fluid was sterile. On the succeeding days the fluid rapidly cleared and cells dropped to 40 , but generalized convulsions and even status epilepticus continued to occur for some days. There was an occasional mucopurulent discharge from a posterior perforation in the right ear, but no radical treatment seemed indicated.

Forty-seven days after admission there was a rise of temperature for no apparent reason, which settled after seven days.

Seventy-five days after admission there was a rise of temperature again, and 77 days after admission the child died in coma, without any explosive episodes.

Necropsy revealed pus in both middle-ear cavities and a sterile exudate around the base of the brain and brain-stem, with no other evident reasons for death.

The cause of failure in all these cases except No. 1 is not obvious, but is evidently various. In none was there the slightest evidence of C.S.F. blockage, and only in Case 4 can it be said that there was undue delay before the start of therapy, whereas in Case 7 the meningitis actually developed under the eye of the physicians and was promptly treated. No penicillin-insensitive organisms were ever isolated. It would seem that the finest present day treatment cannot be guaranteed to sterilize the C.S.F. even in uncomplicated cases, and even if the C.S.F. is cleared residual intracranial damage may sometimes progress to death.

\section{Therapeutic Considerations}

The present standard method of treatment using intrathecal penicillin, with its attendant dangers and difficulties, is fully described by Cairns (Smith et al., 1946), so that the intention in this article is merely to consider one or two particular points.

By ' standard' treatment is meant the injection of pure penicillin intrathecally, 10,000-20,000 units 12-hourly initially, and then once daily; penicillin intramuscularly, about $1,000,000$ units daily in divided doses; and a sulphonamide given in full doses, say, $1 \mathrm{~g}$. per stone per day for an adult. This treatment should be continued for at least a week after the C.S.F. is sterile.

Dosage of Intrathecal Penicillin. Single doses of 40,000 units and over have often been found to produce toxic reactions (Cairns et al., 1944; Sweet et al., 1945; Walker, 1947) and these have included 
arachnoiditis, myelitis, paraplegia, cauda equina damage, pain and weakness in the upper limbs, and convulsions. On the other hand Reuling and Cramer (1947) used 50,000 units repeatedly and never saw any damage result. Reitz (1946) gave 100,000 units 12 -hourly to one case without any deleterious reaction. Neymann (1945) found 40,000 units of $40 \%$ purity satisfactory in general paralysis of the insane, and recent accounts of influenzal meningitis have included this range of dosage (Gerrard, 1947; Gottlieb et al., 1947). In the present series doses of 50,000 units and over (in two cases a few repeated doses of 200,000 units) were often used without any ill effects. Under 20,000 units a day is probably too little, and there are some patients who seem to need considerably more (see Case 8). Certainly this may be given in divided doses 12-hourly, but with the now generally used pure crystalline $G$ salt a large intrathecal dose can be tolerated, and indeed no reports have been found of toxic reaction to any dosage of the pure salt, either clinically or experimentally. The use of intrathecal penicillin has not increased the incidence of convulsions in pneumococcal meningitis, but rather the reverse, as the figures from the present series suggest:

In 107 pre-penicillin cases, fits were recorded in 29 (27\%).

In 56 penicillin-treated cases, fits were recorded in $8(14 \%)$.

The following case (Case 8) is an interesting illustration of some of the preceding points.

Case 8. A boy aged 18 months was admitted to hospital, having been ill for two days and showing signs of right apical pneumonia. The neck was rigid, but lumbar puncture revealed a clear C.S.F. He was treated with sulphamezathine. Two days after admission there was complete right third nerve palsy and gross right orbital oedema. The C.S.F. was now turbid, and pneumococci were found on smear and culture. Pure penicillin, 20,000-50,000 units daily intrathecally, at first in divided and later in single doses, was given, together with 20,000 units intramuscularly four-hourly, and sulphamezathine $0.7 \mathrm{~g}$. four-hourly. The C.S.F. was sterile after 48 hours. Six days after admission the baby was much improved in every way, and the C.S.F. was still sterile. A blood count showed a leucopenia (under 1,000 polymorphs). The sulphamezathine dosage was reduced to $0.4 \mathrm{~g}$. four-hourly.

The white count rose steadily in succeeding days, despite continuation of sulphonamide.

Eleven days after admission the intrathecal penicillin and sulphamezathine were discontinued, but 13 days after admission there was a recurrence of symptoms and of bacteria in the C.S.F. on smear and culture, and the full therapy was resumed.

Twenty-three days after admission the baby had developed a sero-purulent discharge from the right ear, but surgery was not indicated. Twenty-seven days after admission the child seemed well, and again the intrathecal penicillin and sulphamezathine was discontinued.

However, 28 days after admission there was a second clinical and bacteriological relapse, and full therapy was resumed.

After this there was consistent clinical improvement, no further rise of temperature, and complete recovery of the third nerve palsy, despite three further bacterial relapses during the next three weeks. These relapses were accompanied by a consistent fall in the protein level and in cells in the C.S.F., although intrathecal penicillin was continued in high dosage. In two relapses the cocci were grown in culture, but in the third they were seen only on the smear.

Treatment was continued (with breaks only as indicated above) for eight weeks, and the residual penicillin in the C.S.F. was estimated daily. The persistence of penicillin was found to be extremely variable. No trace was ever found after less than 50,000 units given during the preceding 24 hours and on this dosage the residual drug varied from 0 to 7 units per ml. Even when given 12-hourly at least 25,000 units were needed to produce any persistence at the time of the next injection. This case also indicates the importance of long-continued, intensive therapy.

Are Intrathecal Injections Necessary? Despite the contention of Rosenberg and Sylvester (1944) that 24-40,000 units of penicillin administered intramuscularly or intravenously were sufficient to produce reasonable penetration into the C.S.F. in meningitic cases, the consensus of opinion has been that intrathecal therapy is necessary in pneumococcal meningitis (Rammelkamp and Keefer, 1943; Cairns and Smith et al., 1944, 1946; Anderson, 1945; Smith, 1945; Ross and Burke, 1946). More recently, however, Lowrey and Quilligan (1948) reported 14 recoveries out of 17 cases without intrathecal penicillin. All the last seven cases recovered. These received 100,000 units intravenously repeated twice and followed by 400,000 units daily intramuscularly, together with sulphadiazine in doses of $1 \cdot 5 \mathrm{~g}$. per stone bodyweight per day. Dowling et al. (1949a) treated 21 cases with doses of $1,000,000$ units intramuscularly two-hourly and found $0 \cdot 08-1 \cdot 25$ units per ml. in the C.S.F. after eight hours. Only two cases died after being treated more than 24 hours. The authors were encouraged to give such large doses by the report of Schwemlein et al. (1946), who showed that penicillin penetrated into the C.S.F. in therapeutic quantities in $100 \%$ of people who received $20,000,000$ units in 24 hours, and also by their own series of 16 cases in which intrathecal penicillin was used with only seven recoveries. Dowling and his co-workers in a further report (1949b), remarked on a more rapid fall in temperature and in pleocytosis in the C.S.F. using intramuscular therapy only. Sulphonamides were found to be unnecessary. Other authorities commenting on this report (Spink, 1949; Boger, 1949) agreed that penicillin given in this way appeared completely 
adequate. It would seem, then, that this method of therapy should be more widely tried, since it obviates the difficulties and dangers of multiple intrathecal injections and may, perhaps, produce even better results. Incidentally Duthie (1944) showed that 1/40 unit of penicillin per $\mathrm{ml}$. was usually lethal for the pneumococcus, and there is no evidence that penicillin resistance ever develops in a case under treatment. It must be pointed out that the value of this type of therapy in infants has not yet been assessed.

Are Pneumococei in C.S.F. Always Pathogenic ? Occasionally it was observed that a bacterial relapse in the C.S.F. was unaccompanied by concomitant clinical signs, and that the patient's recovery was, in fact, quite unimpeded despite the renewed presence of pneumococci. In these circumstances there was no accompanying rise in cells, nor in protein levels, nor any fall in chloride or sugar levels in the C.S.F., and in fact the improvement in these findings continued uninterruptedly. Patient No. 8 is an example. During his last relapses the cells in the C.S.F. were below 10 per c.mm. It is suggested therefore that in certain bacterial relapses the pneumococci are actually non-pathogenic and their finding then is evidence of a symptomless infection, partially comparable with some Bact. coli bacillurias, or with the excretion of typhoid bacilli from a carrier's gall bladder.

This suggestion has also been made by Traut
(1945), who reported an interesting case in which pneumococci recurred in the C.S.F. for several months at approximately monthly intervals. I did not know of Traut's case when this idea occurred to me.

The Special Problem of the Young Infant

Recovery in infants was extremely uncommon before the advent of penicillin. Now, however, some of the poor results are undoubtedly related to difficulty and delay in the diagnosis of meningeal disease. Since such excellent results have been obtained by some physicians (White et al., 1945; Ross and Burke, 1946; Alexander, 1947) an awareness of the difficulties of early diagnosis in the infant is evidently of great importance. Metcalfe (1948) has reported a recovery in an infant who was eight days old when the meningitis was diagnosed, but who was in hospital at the time and was promptly treated.

Alexander and Ellis (1942) and Alexander in 1943, commenting on the diagnostic difficulties in infants under seven months, drew attention to the importance of a slight increase in tension of the fontanelle, alternating drowsiness and irritability, a high pitched cry, and a vacant look in the eyes, especially when any of these are combined with fever. Hogg and Bradley (1945) remark that the presenting symptom may be vomiting, diarrhoea, irritability, otitis media, or pyrexia of unknown cause, while the occurrence

TABLE 7

Survey of Clinical. Features of Twenty Cases

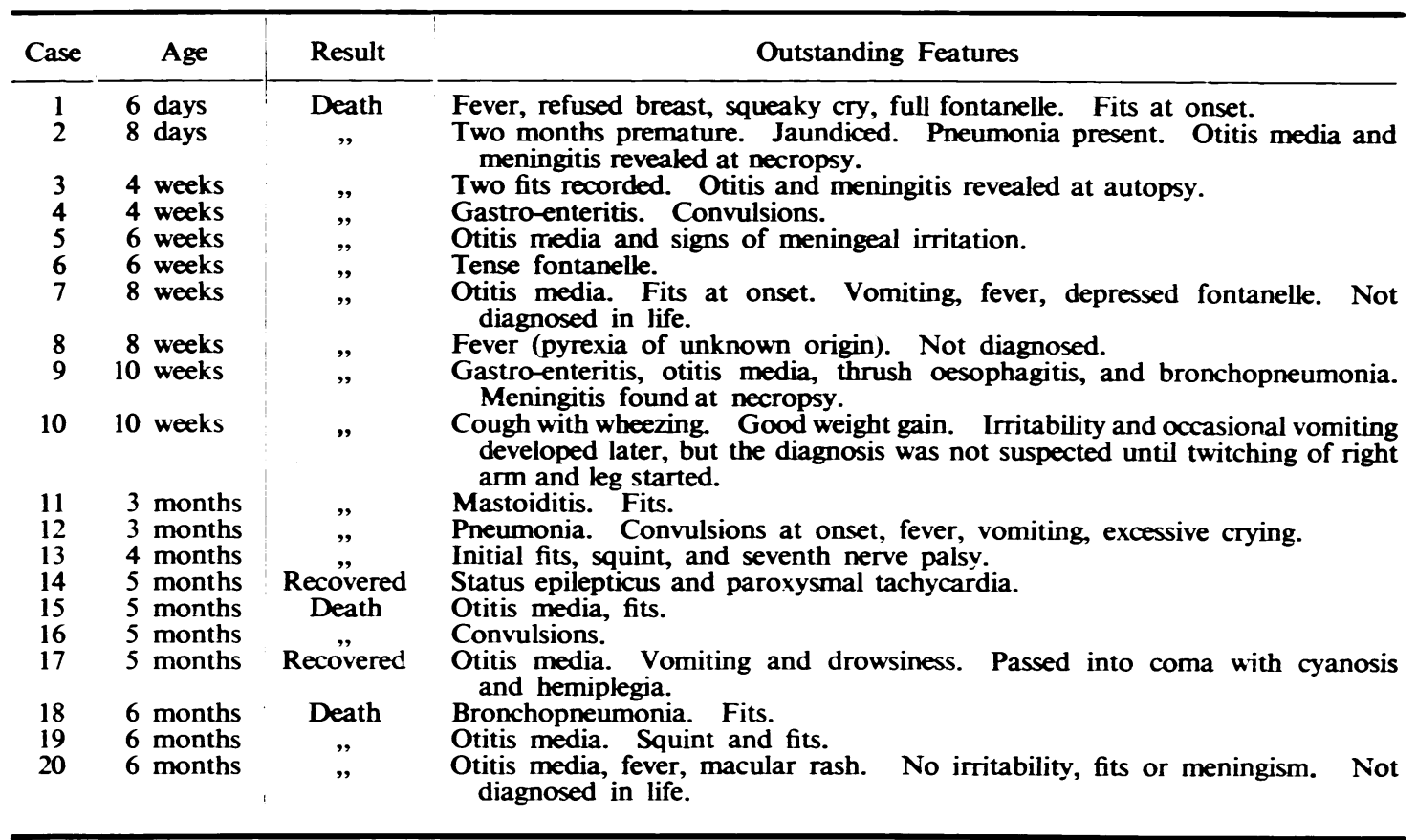


of convulsions with any of these strongly suggests meningeal involvement. Even in pre-chemotherapeutic days the difficulties in making this diagnosis were pointed out by Koplik (1916) and Cooperstock (1938).

Twenty case records of patients under seven months of age in the present series have been surveyed, in the hope of helping to assess which clinical features might be of the greatest value as diagnostic pointers. They are summarized in Table 7 .

Of these 20 cases diagnosis was made only at necropsy in six, and was too late in several others to be of any value. It is noteworthy that $13 \mathrm{had}$ convulsions, mostly at the onset of the disease. Eight cases showed neither signs of meningeal irritation nor tenseness of the fontanelle. In fact the limb signs of meningitis (Kernig, Brudzinski) appeared quite valueless. Stiffness of the neck, a sign of greater importance, is difficult to assess in the infant. When present it may be noticed that the baby prefers to lie on his side rather than on his back, so as to allow slight retraction of the head to occur even when the neck is not markedly stiff. The best test for minor degree of neck rigidity is gently lifting the head with the flat hand behind the occiput of a quiet infant, when, in a normal baby who is not crying, the chin immediately collapses on to the chest.

Middle-ear disease accompanied the meningitis in ten cases, pneumonia in three, and gastro-enteritis in two.

It would seem that meningitis should be suspected and lumbar puncture performed in the following circumstances, even in the absence of any confirmatory signs.

(1) Otitis media with fever which does not immediately respond to therapy.

(2) Vomiting not due to obvious cause, especially if accompanied by fever.

(3) Unusual drowsiness and lack of interest in food.

(4) Change in type of cry; excessive crying and irritability.

(5) Convulsions occurring for the first time, even if with no other symptoms.

(6) Tense fontanelle.

(7) The development of paralytic phenomena, e.g. squint.

Particularly dangerous is the tendency to consider fits to be the natural concomitants of teething, otitis, pneumonia, feeding disturbance, etc. Intracranial disease should always be suspected.

Therapy in young infants is usually on the same lines as in older people, but Alexander (1947) has claimed improved results from the addition of intravenous specific rabbit antiserum. She had six recoveries in eight infants under six months old using her serum together with standard penicillin and sulphonamide treatment.

\section{Summary}

An attempt has been made to trace the development of the recent therapy of pneumococcal meningitis and to note its effect in progressively lowering the mortality rate of this disease. A series of 163 cases occurring in Birmingham during the last 11 years. has been analysed. It is evident that the prognosis of pneumococcal meningitis in general is not as good as we might expect, although the causes of failure in therapy are not always obvious.

The special problem of diagnosis in the infant has been considered, since the signs of meningeal infection at this age are usually atypical and frequently misinterpreted. Recent trends in the methods of using penicillin are discussed, and it seems possible that very large doses of this drug given intramuscularly may obviate the necessity for intrathecal injections and the use of sulphonamide.

I am greatly indebted to the superintendents and physicians of the King Edward VII Hospital, Birmingham, Selly Oak Hospital, Dudley Road Hospital, Birmingham, and Little Bromwich Fever Hospital for access to case records, and particularly to Dr. Margaret Ingham for her help in collecting data, and to Professor Forman for his advice.

\section{REFERENCES}

Adam, J., and Connal, E. A. M. (1937). J. Laryng., $52,87$.

Alexander, H. E. (1943). Amer. J. Dis. Child., 66, 172. (1947). Advances in Pediatrics, 2, 121.

- Ellis, C., and Leidy (1942). J. Pediat., 20, 673.

Allman, C. H. (1937). Arch. Otorhinolaryng., 25, 653. Anderson, D. G. (1945). New Engl. J. Med., 232, 400. Appelbaum, E. (1945). Clinics, 4, 396.

-, and Nelson, J. (1945). J. Amer. med. Ass., 128, 778.

Barker, L. F. (1943). Amer. J. med. Sci., 206, 701.

Boger, W. P. (1949). J. Amer. med. Ass., 139, 757.

Cairns, H., Duthie, E. S., Lewin, W. S., and Smith, H. (1944). Lancet, 1, 655.

Caldwell, J. R., and Byrne, P. S. (1937). Brit. med. J., 1, 1204.

Cooke, J. V., and Goldring, D. (1945). J. Amer. med. Ass., 127, 80.

Cooperstock, M. (1938). J. Mich. med. Soc., 37, 698.

Dowling, H. F., Dauer, C. C., Feldman, H. A., and Hartman, C. R. (1942). New Engl. J. Med., 226, 1015.

—, Sweet, L. K., Robinson, J. A., Zellers, W. W., and Hirsch, H. L. (1949a). Amer. J. med. Sci., 217, 149.

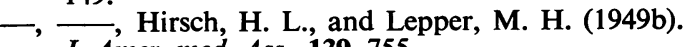
J. Amer. med. Ass., 139, 755.

Duthie, E. S. (1944). Brit. J. exp. Path., 25, 96.

Finland, M., Brown, J. W., and Raub, A. E. (1938). New Engl. J. Med., 218, 1033.

Gerrard, J. (1947). Lancet, 2, 167.

Goldstein, H. I., and Goldstein, H. Z. (1927). Internat. Clinics., 3, 155.

Gottlieb, B., Forsyth, C. C., and Arlott, E. N. (1947). Lancet, $2,164$.

Hall, W. H., Alden, J., Burt, G. M., and Spink, W. W. (1946). Minn. med., 29, 553.

Hewell, B. A., and Mitchell, A. G. (1939). J. Amer. med. Ass., 112, 1033. 
Hodes, H. L., Smith, M. H. D., and Ickes, H. J. (1943). J. Amer. med. Ass., 121, 1334.

Hogg, P., and Bradley, C. D. (1945). J. Pediat., 26, 406.

Hutchins, G., and Davies. J. A. V. (1945). J. Pediat., $27,505$.

Jacobsen, E. (1945). Nord. Med., 27, 1473.

Jaffe, I. P. (1946). Clin. Proc., 5, 345.

Keefer, C. S., Blake, F. G., Marshall, E. K., Lockwood, J. S., and Wood, W. B. (1943). J. Amer. med. Ass., 122, 1217.

Klepacki, W. (1947). Polsk. Tyg. lek., 2, 678 (v. Abst. Wld. Med., 1948, 3, 159.)

Koplik, H. (1916). Arch. Pediat., 33, 481.

Leyshon, V. N. (1942). Lancet, 1, 352.

Lowrey, G. H., and Quilligan, J. J. (1948). J. Pediat., 33, 336.

MacKeith, R. C., and Oppenheimer, G. (1939). Lancet, 1, 1099.

Mertins, P. S., and Mertins, P. S., Jr. (1937). Arch. Otolaryng., Chicago, 25, 657.

Metcalfe, E. M. (1948). Brit. med. J., 2, 860.

Neal, J. B., Appelbaum, E., and Jackson, H. W. (1940). J. Amer. med. Ass., 115, 2055.

Neymann, C. A. (1945). Arch. Neurol. Psychiat., Chicago, 54, 311.

Peittsara, H. (1947). Ann. Med. intern. fenn., 36, 594.

Raman, P. S. (1939). Lancet, 1, 1101.

Rammelkamp, C. H., and Keefer, C. S. (1943). J. clin. Invest., 22, 425.

Reitz, C. B. (1946). Hahnemann Mthly., 81, 1.

Reid, G. C. K., and Dyke, S. C. (1938).' Lancet, 2, 619.
Reuling, J. R., and Cramer, C. (1947). J. Amer. med. Ass., 134, 16.

Rhoads, P. S., Hoyne, A. L., Levin, B., Horswell, R. G., Reals, W. H., and Fox, W. W. (1940). J. Amer. med. Ass., 115, 917.

Rosenberg, D. H., and Sylvester, J. C. (1944). Science, $100,132$.

Ross, S., and Burke, F. G. (1946). J. Pediat.. 29, 737.

Schwemlein, G. X., Barton, R. L., Bauer, T. J., Loewe, L., Bundesen, H. N., and Craig, R. M. (1946). J. Amer. med. Ass., $130,340$.

Silverthorne, N. (1948). Can. med. Ass. J., 58, 255.

Smith, H. (1945). Proc. R. Soc. Med., 38, 610.

Smith, H. V., Duthie, E. S., and Cairns, H. (1946). Lancet, 1, 185.

Spink, W. W. (1949). J. Amer. med. Ass., 139, 757.

Steele, C. W., and Gottlieb, J. (1941). Arch. intern. Med., 68, 211.

Sweet, L. K., Dumoff-Stanley, E., Dowling, H. F., and Lepper, M. H. (1945). J.'Amer. med. Ass., 127, 263.

Toomey, J. A., and Roach, F. E. (1939). Ohio St. med. J., 35, 841.

Traut, E. F. (1945). J. Amer. med. Ass., 129, 273.

Walker, A. E. (1947). Arch. Neurol. ? Psychiat., 58, 39.

Walker, H., and James, G. W. (1945). Virg. med. Mon., 72, 276.

Waring, A. J., and Smith, M. H. D. (1944). J. Amer. med. Ass., 126, 418.

White, W. L., Murphy, F. D., Lockwood, J. S., and Flippin, H. F. (1945) Amer. J. med. Sci., 210, 1. 